\title{
SLAVOJ ZIZEK: SUJEITO, SABER CIENTÍFICO E DO INCONSCIENTE E ATO EDUCATIVO
}

\author{
Hildemar Luiz Rech ${ }^{1}$
}

Resumo

No cerne do enfoque lacaniano de Zizek, o sujeito da enunciação inconsciente tem prevalência sobre o sujeito do enunciado, tornando o sujeito cindido. Embora desde as formações inconscientes, o sujeito é um efeito da linguagem, ele ademais comporta uma relação espinhosa com toda a cadeia de significantes. De modo semelhante, o sujeito hegeliano também não é autoidentificado e transparente em termos de sua consciência, visto que inclui um elemento de nãoidentidade. Quanto ao binômio saber inconsciente e conhecimento científico, o primeiro faz emergir falhas e furos que põe em xeque a consistência/totalidade da ciência moderna, apontando para o não-todo e a negatividade implícita em todo o saber. Por fim, a emancipação social implica o ato político e educativo de superação das coordenadas gerais do "status quo".

Palavras-chave: Sujeito, saber inconsciente, conhecimento científico e ato educativo.

\begin{abstract}
:
In the core of the lacanian approach of Zizek, the subject of unconscious enunciation is prevalent regarding to the subject of enunciate, which makes the own subject divided. Taking into account the unconscious formations, even if the subject is an effect of language in them, the own subject embraced also an uncomfortable and thorny relationship with the significant unconscious linguistic network. Otherwise, the Hegelian subject is also not auto-identified and transparent in his consciousness, since it includes a non-identity component. As regards the binomial combining, unconscious knowledge and scientific knowledge, the first of them makes appear holes, faults and gaps which call into questioning the consistency/totality of modern science, pointing to the implicit non-totality and negativity in all kind of knowledge. Finally, social emancipation implies a political and educational action, aiming to overcome the general coordinates of the "status quo".
\end{abstract}

Keywords: Subject, unconscious knowledge, scientific knowledge and educational action.

\section{Introdução}

De modo controvertido, Zizek apropriou-se do pensamento de Lacan e de Hegel

endossando os compromissos da modernidade, referenciando a sua construção teórica

\footnotetext{
${ }^{1}$ Professor Associado III do Departamento de Fundamentos da Educação e do Programa de Pós-Graduação em Educação da Universidade Federal do Ceará (UFC). Doutor em Ciências Sociais pela Universidade Estadual de Campinas (UNICAMP) e pela Universidade de Manchester, UK. Pesquisador colaborador nos Programas PROCAD/CAPES e do LABOR/UFC. Membro integrante e vice-coordenador do eixo Filosofia, Política e Educação na linha de pesquisa Filosofia e Sociologia da Educação na Pós-Graduação de Educação da UFC. E.mail: rechhl@pop.com.br
} 
em torno do sujeito cartesiano e do potencial libertador de sua agência autorreflexiva, porém, com restrições a uma compreensão autotransparente do sujeito, visto que este é concebido como visceralmente entrelaçado com o caráter predominante do sujeito da enunciação inconsciente, de cuja inscrição significante, com seus cortes traumáticos, emerge paradoxalmente, segundo este autor (2010), uma formação de restos e excessos atados ao registro do Real (impossível de ser simbolizado), na forma de "objetos a" enquanto objetos do desejo enviesados com a dinâmica das pulsões e do gozo.

\section{Breves Considerações Sobre o Sujeito Barrado, o "Grande Outro", o Objeto-Causa do Desejo, o "Objeto Pequeno a", a Ideologia e a Fantasia}

Conforme Zizek (2009), o sujeito barrado lacaniano (\$), antes de ser captado na identificação, no reconhecimento/desconhecimento simbólico, é captado pelo Outro (a máquina significante) por meio de um paradoxal objeto-causa do desejo em meio a isso, (o objeto pequeno a, para sempre perdido), mediante o segredo supostamente oculto no "grande Outro", que se exprime na fórmula do "Sujeito barrado punção objeto $\alpha$ " $(\$ \diamond a)$ - que é a fórmula lacaniana da fantasia. Isto também significa que, de acordo com a concepção fundamental de Lacan, existe a possibilidade de o sujeito adquirir alguns conteúdos e uma determinada consistência positiva, fora do "grande Outro" - enfim fora da rede simbólica intersubjetiva alienante. Essa outra possibilidade é oferecida pelo equacionamento do sujeito como objeto da fantasia.

Ademais, a fantasia contribui para a estruturação da própria realidade, visto que a configuração desta envolve uma construção fantasiosa que permite mascarar o Real traumático do nosso desejo. Para Zizek, sucede o mesmo com a ideologia. A fantasia, em seu sentido fundamental, é um paradoxo ontológico:

\footnotetext{
[Cujo escândalo] (...) reside no fato de que ela subverte a oposição típica do 'subjetivo' e 'objetivo': é claro, a fantasia é por definição não objetiva, 'ou seja, ela não é algo' que existe livre das percepções do sujeito; porém, ela é também não subjetiva, 'ou seja, ela não é algo que pertence às intuições conscientemente experimentadas do sujeito como o produto de sua imaginação. A fantasia pertence antes à 'bizarra categoria do objetivamente subjetivo - o modo como as coisas objetivamente parecem ser para você (ZIZEK, 2010, p. 66).
}

$\mathrm{Na}$ fantasia, portanto, ocorre a incidência de determinadas crenças e suposições negadas que sequer sabemos que abrigamos, mas que determinam nossos atos e sentimentos. O cerne da fantasia é então o saber do próprio inconsciente freudiano. "Esta é também uma das maneiras de especificar o significado da afirmação de Lacan de que o sujeito é sempre descentrado" (ZIZEK, 2010, p. 67).

\begin{tabular}{|l|l|l|l|l|} 
Revista Dialectus & Ano 1 & n. 1 & Julho-Dezembro 2012 & p. 200-218 \\
\hline
\end{tabular}


Segundo Zizek, o que Lacan quer dizer com esta argumentação não é que a nossa experiência subjetiva seja regulada por mecanismos inconscientes objetivos que são descentrados em relação à nossa experiência de nós mesmos e, como tal, fora de nosso controle, mas que ocorre algo muito mais perturbador conosco. Ou seja, que

[...] estamos privados até [do controle] de nossa experiência subjetiva mais íntima, ou seja, do modo como as coisas [realmente parecem ser para nós] (ZIZEK, 2010, p. 67-68).

Nestes termos estou privado da fantasia fundamental que constitui e garante o cerne de meu ser, uma vez que nunca posso experimentá-la e assumi-la explicitamente. Ou seja, para Zizek:

\begin{abstract}
O sujeito freudiano do inconsciente só emerge quando um aspecto essencial da auto-experiência do sujeito, qual seja, a sua fantasia fundamental, torna-se inacessível para ele, ou seja, torna-se primordialmente recalcada. [Em outras palavras], em seu aspecto mais radical, o inconsciente é um fenômeno inacessível e não os mecanismos objetivos que regulam minha experiência fenomênica. (ZIZEK, 2010, p. 68).
\end{abstract}

Estamos, assim, tratando com uma noção de subjetividade humana em que há um hiato que separa o sujeito de sua fantasia fundamental. "É essa inacessibilidade que torna o sujeito 'vazio' [em termos ontológicos]” (ZIZEK, 2010, p. 69).

Impõe-se, deste modo,

[...] uma relação que subverte a noção corrente do sujeito que experimenta a si mesmo através de seus estados interiores. [Ocorrendo] (...) uma estranha relação entre um sujeito vazio, não fenomênico, e os fenômenos que permanecem inacessíveis ao sujeito. (ZIZEK, 2010, p. 69)

Interpõe-se, assim, pela psicanálise, uma paradoxal fenomenologia que compreende a emergência de experiências descoladas de um sujeito, mas que mesmo assim aparecem para este sujeito.

Isto não significa que o sujeito não esteja envolvido aqui - ele está, mas precisamente no modo da exclusão como dividido, como a agência que não é capaz de assumir o cerne de sua experiência interior. (ZIZEK, 2010, p. 69)

Nesta perspectiva apresenta-se um hiato que separa persistentemente

[...] o núcleo fantasístico do ser do sujeito dos modos mais artificiais de suas identificações simbólicas ou imaginárias. [Assim,] nunca me é possível assumir plenamente em termos da integração simbólica o núcleo fantasístico do meu ser. (ZIZEK, 2010, p. 70)

Ou seja, quando apresento a audácia de deparar-me frontalmente com a minha fantasia fundamental, estabelece-se aquilo "[...] que Lacan chama de afânise (a autoobliteração) do sujeito: o sujeito perde sua consistência simbólica” (ZIZEK, 2010, p. 71). 
Nestes termos, o sujeito é atravessado por um violento solapamento da própria base de sua identidade e de sua autoimagem, a ponto de desintegrar-se, pois o cerne de sua fantasia lhe é intolerável. Esta apresenta uma ambiguidade fundamental, pois, se por um lado, ela funciona como o crivo que nos protege do encontro com o Real traumático, por outro lado, ela, a fantasia, naquilo que ela tem de mais fundamental, nunca pode ser subjetivada, precisando permanecer recalcada para funcionar (ZIZEK, 2009).

Em sua dimensão básica, também a ideologia é uma construção 'da fantasia que serve de esteio à nossa própria "realidade": uma "ilusão" que estrutura nossas relações sociais reais e que, com isso, "mascara um insuportável núcleo real”, um "antagonismo social traumático" (de classes, racial, sexual, ou outro) que não pode ser simbolizado. Desse modo, como observa Zizek:

A função da ideologia não é oferecer-nos uma via de escape da nossa realidade, mas oferecer-nos a [construção da] realidade social como uma fuga de algum núcleo real traumático. (ZIZEK, 1996B, p. 323).

Conforme Zizek (2009), o sujeito marcado por uma fantasia fundamental, falha no reconhecimento de si mesmo devido ao seu inexorável entrelaçamento com um objeto especial que é objeto causa de seu desejo, ou seja, o objeto pequeno a que é o objeto para sempre inalcançável ou perdido dentro do campo dos objetos por ele percebidos. Assim, em termos daquilo que unifica esta noção psicanalítica com a filosofia política de Zizek, pode-se dizer que este objeto pequeno a é exatamente um “objeto sublime”. É um objeto que, em termos freudianos, é "sublimado" pelo sujeito até o ponto em que ele se ergue como um representante metonímico do gozo do sujeito, o qual as fantasias inconscientes extraíram da castração ou do recalcamento.

Isto, portanto, funciona como o objeto causa do desejo, cuja excepcional "pequena partícula ou parte do Real" o sujeito procura colher em todas as suas relações de amor. Por outro lado, nem a voz e nem o olhar, enquanto objeto pequeno a, atestam a capacidade soberana do sujeito de objetivar e, consequentemente, controlar o mundo. Ou seja, no campo visual e auditivo, respectivamente a voz e o olhar, como objeto pequeno a, representam os objetos como coisas sublimes, tal como as coisas sublimes de Kant, as quais o sujeito não consegue cercar integralmente com as categorias da sensibilidade e com os juízos do entendimento. O fato de que estas coisas sublimes só podem ser vistas ou ouvidas a partir de perspectivas particulares, indica exatamente como o prisma enviesado e distorcido do sujeito - e assim o seu desejo, ou seja, o que o sujeito quer tem um efeito sobre o que ele é capaz de ver. Então, é desse modo que 
estes objetos sublimes dão testemunho de como o sujeito não pode se colocar em uma posição de neutralidade porque lhe é impossível colocar-se totalmente fora da realidade que ele vê, em consequência não podendo ocupar a posição de um olhar neutro, à medida que seu desejo (inconsciente ou não) condiciona seu olhar.

Segundo Zizek (2010), o objeto pequeno a, para sempre perdido, se impõe como o oposto exato do objeto das ciências modernas, o qual é enfocado de modo totalmente impessoal e abordado de modo claro e distinto. O objeto pequeno a ou é visto a partir de uma perspectiva subjetiva particular, com um olhar distorcido, ou não pode ser visto de modo algum. É por isso que Zizek considera que a noção psicanalítica do objeto pequeno $a$ pode ser utilizada para constituir nossa compreensão dos “objetos sublimes" postulados pelas ideologias na esfera do político, objetos estes que se mostram inconsistentes quando finalmente são abordados de forma desapaixonada.

O que então a crítica da ideologia de Zizek (1996A) pretende fazer, com o uso desta noção psicanalítica, é demonstrar as inconsistências que estão instaladas no cerne das fantasias ideológicas e, desse modo, mostrar-nos que os objetos mais centrais e consagrados que sustentam nossas convicções políticas são coisas (Ding) que, com sua aparência muito sublime, escondem de nós o agenciamento e o engajamento ativo e sem sentido de nosso próprio organismo vivo, na maioria das vezes alienadamente, que constrói e sustenta a sublimidade destes objetos. Ademais, quando um sujeito acredita em uma ideologia política, isso não significa que ele sabe a verdade sobre os objetos sublimes que permitem a estabilização desta ideologia na forma de um regime político.

\section{O Sujeito Kantiano do Conhecimento, O Sujeito Hegeliano como "Noite Do Mundo" e o Sujeito de Zizek como uma Fenda ou uma Dobra na Realidade}

Outra questão fundamental que ainda se coloca não é se há realidade fora da mente, mas de que não há mente fora da realidade. Ou seja, a questão central não é se a realidade existe independentemente da mente, do "Eu penso", mas o fato de a mente, com suas faculdades de percepção e entendimento, fazer parte da própria realidade, de modo que ela não poder se situar de forma neutra em relação a esta. Assim o conhecimento da própria realidade resulta de uma perspectiva subjetiva distorcedora inerente às próprias faculdades de conhecimento do sujeito. E "se retirarmos essa perspectiva distorcida, perdemos a própria coisa em si” (ZIZEK, 2006, p. 120).

Isso significa o seguinte:

\begin{tabular}{|l|l|l|l|l|}
\hline Revista Dialectus & Ano 1 & n. 1 & Julho-Dezembro 2012 & p. 200-218 \\
\hline
\end{tabular}


Em termos objetivos, nada existe [como uma realidade fechada em si], e as entidades só emergem como resultado da diferenciação de perspectivas, [numa visão em paralaxe], na qual toda diferenciação é uma distorção parcial. (ZIZEK, 2006, p. 121).

Ou seja, a distorção da realidade ocorre, precisamente, porque nossa mente faz parte da realidade. Desse modo, segundo Zizek (2006, p. 121-122):

\begin{abstract}
A verdadeira fórmula do materialismo não é a de que existe uma realidade "numenal" [inacessível em si] além da percepção distorcida que temos dela. A única posição materialista coerente é que o mundo não existe - no sentido kantiano do termo - como uma "coisa-em-si" toda fechada em si mesma, [como um "noumenon", como uma essência inatingível]. A idéia do mundo como um universo 'plenamente' positivo pressupõe um observador externo que não esteja preso dentro dele. A própria posição da qual se pode perceber o mundo como um todo fechado em si mesmo é a posição do observador externo, [que não é o caso do conhecimento humano]. Paradoxalmente, portanto, é esse perspectivismo radical que nos permite formular uma postura de fato materialista, não porque o mundo existe fora da nossa mente, mas porque nossa mente não existe fora do mundo.
\end{abstract}

Ademais, na defesa do sujeito cartesiano, Zizek toma seus próprios apontamentos de sua leitura lacaniana de Kant. Ou seja, na "Dialética Transcendental", em a Crítica da Razão Pura, Kant criticou o argumento cartesiano da autogarantia do "Eu penso", quanto à sua necessidade de ser uma coisa pensante (res cogitans). Para Kant, embora o "Eu penso" deva ser capaz de acompanhar todas as percepções do sujeito, isto não significa que ele próprio é um objeto substancial. Nesta perspectiva, o sujeito que vê os objetos do mundo não pode ver-se a si mesmo vendo, mais do que uma pessoa que salta sobre a sua própria sombra. À medida que um sujeito pode ver-se reflexivamente, ele vê-se não como um sujeito, mas mais como um objeto representado, que Kant chama de "eu empírico", ou o que Zizek chama de “eu” [narcísico e imaginário-simbólico], em oposição ao sujeito (ZIZEK, 1997).

O sujeito sabe que é algo, mas nunca pode saber que coisa é na realidade. É por isso que ele precisa procurar pistas sobre a sua identidade na sua vida política e social, perguntando a respeito aos pequenos outros e principalmente ao "grande Outro", ou seja, à rede simbólica intersubjetiva estabilizadora e alienante, impactada no campo social. Então, segundo Zizek, o sujeito se interroga frente ao "grande Outro" com um "O que você quer de mim?", o que acaba definindo o sujeito como tal.

Assim, segundo Zizek (2006), o sujeito é uma fenda no campo do universal, não uma coisa cognoscível. É por isso que Zizek repetidamente cita em seus livros a passagem perturbadora do jovem Hegel que descreve o sujeito moderno não como uma luz do moderno iluminismo, mas como "esta noite do mundo, este nada vazio". E isto é crucial para a posição de Zizek, que nega a aparente implicação daquilo pelo qual o

\begin{tabular}{|l|l|l|l|l|} 
Revista Dialectus & Ano 1 & n. 1 & Julho-Dezembro 2012 & p. 200-218 \\
\hline
\end{tabular}


sujeito é algo como uma espécie de entidade suprassensível, como, por exemplo, uma alma imaterial e imortal. Em outras palavras, o sujeito é o ponto dentro da substância da realidade em que esta é capaz de olhar para si mesma, como estranha para si mesma. Ou seja, segundo o filósofo esloveno (1993), o sujeito não é algum tipo especial de coisa fora da realidade fenomenal que podemos experimentar, pois ele é apenas uma dobra ou um vinco na própria realidade fenomenal. Hegel e Lacan, segundo Zizek (2006), adicionam à leitura de Kant, que aborda o sujeito como o vazio "Eu penso" que acompanha qualquer experiência individual, a ressalva de que, devido ao fato de que os objetos, em sua abordagem sempre já implicam a perspectiva do sujeito, eles aparecem sempre de forma incompleta, inadequada, distorcida e parcial. Ademais, isto significa que inclusive o sujeito, em sua "fantasia fundamental", falha no reconhecimento de si mesmo como um objeto especial, dentro do campo de objetos que percebe.

Para Zizek (1997), a civilização dos indivíduos ou sujeitos, necessita ademais do sacrifício fundador ou da castração do gozo, com a sua promulgação em nome da lei sociopolítica. Assim, os indivíduos são civilizados, à medida que são obrigados por lei social a perseguir este objeto especial que é o objeto pequeno $a$ - na leitura psicanalítica - e o "objeto sublime" na leitura político-filosófica. Mas, devem fazê-lo, sem se descuidar da observação das convenções sociais linguisticamente mediadas, adiando a satisfação libidinal de gozo e aceitando a diferença sexual e de gerações.

Assim, a fantasia fundamental do sujeito também é uma estrutura inconsciente que permite ao sujeito aceitar a perda traumática envolvida no sacrifício fundador ou na castração. Ou seja, ela re-significa a repressão fundadora do gozo pela lei, o que se torna necessário para que o indivíduo se torne um sujeito falante, mas isso ocorre como se fosse uma mera contingência, ou seja, uma ocorrência evitável (ZIZEK, 1997).

\section{A Positividade do Cogito Cartesiano, a Ciência Moderna, o Homem como Habitante da Linguagem, o Sujeito Mutilado, o Desejo e a Pulsão}

Por outro lado, em afinidade com Lacan, Zizek (2009) defende a subjetividade cartesiana, mas pela via de uma inversão, operada de modo paradoxal, que afirma o sujeito do inconsciente como alternativa ao cogito racional de Descartes. Sob este prisma, é preciso ter em conta que o saber do inconsciente não é imediatamente acessível e que a estrutura de sua linguagem significante introduz no campo do saber novidades irredutíveis ao conhecimento científico que se pauta apenas a partir de uma 
lógica empírica, pragmática, racionalista e positivista. Além disso, a "ciência moderna" decorre de um corte epistemológico com a filosofia medieval, ruptura pela qual ocorre um deslocamento de uma visão fechada de mundo, mas metafisicamente fundamentada, para um conhecimento aberto ao universo infinito (ZIZEK \& DALY, 2006).

Descartes, um dos primeiros artífices desta ruptura no campo da reflexão filosófica e que instaurou o espírito da ciência moderna, colocou a dúvida como núcleo fulcral de seu método. Sob este prisma, a própria res cogitans enquanto cogito, enquanto pensamento que pensa, somente garante o pensar e não a questão da corporeidade no espaço, enfim, não garante a problemática da existência do ser como exterioridade natural e material, não garante a res extensa. Assim, para garantir a existência das coisas como substância material e, inclusive, para garantir o próprio sujeito pensante enquanto capaz de subsistir para além de seu próprio pensamento, Descartes teve que recorrer a uma terceira coisa, a Deus, ou seja, à res infinita ou divina. Porém, a maior novidade em Descartes pode ser encontrada no fato de com ele o discurso do saber ter-se voltado pela primeira vez ao agente do saber, tomando também a este como uma questão de saber. Sob este prisma o próprio pensar sobre o ser, ou seja, o próprio pensar do sujeito torna-se pensável, colocando em questionamento os fundamentos ontológico-metafísicos do conhecimento, que assim não se sustentam mais como puros correlatos dos objetos conhecidos no mundo sensível (ZIZEK, 2008).

Contudo, mais adiante, em Kant, o sujeito não aparecerá mais como uma substância pensante consistente, ou seja, não mais é apresentada como uma res cogitans, ao modo de Descartes, mas como Vazio que introduz a Razão no campo do entendimento, concebendo o sujeito de forma transcendental e não de modo individual e psicológico, ademais, sem precisar para isso recorrer à res infinita ou divina. A propósito, é o sujeito vazio e transcendental kantiano, por se coadunar melhor com a ideia do inconsciente freudiano, que interessa mais à teoria psicanalítica de Lacan do que qualquer psicologia naturalista e desenvolvimentista (ZIZEK, 2009).

Na perspectiva lacaniana, segundo Zizek (2009), o homem habita na linguagem, mas sob a condição incômoda expressa na experiência de que essa residência do Ser é uma casa de tortura, onde o sujeito do inconsciente persiste como uma abertura que não se adequa plenamente à lógica de estruturação da cadeia de significantes, não sendo um mero efeito da linguagem, incidindo também como um espinho atravessado na garganta do significante. Ou seja, a passividade do Ser enredado na linguagem comporta um verdadeiro impacto traumático na forma de uma tensão permanente entre o animal 
humano e a linguagem, de modo que o sujeito se constitui porque o animal humano não se ajusta de modo integral à linguagem. Entretanto, sob este prisma, a dimensão mais radical do sujeito, paradoxalmente, é a passividade e a não atividade, ou seja, o ato de suportar e de arcar o impacto cortante e atormentador da linguagem.

Por outro lado, contudo:

\begin{abstract}
A mutilação [do sujeito] serve para orientar o desejo, capacitando-o a assumir precisamente essa função de índice, de qualquer coisa já realizada e que só poderá ser articulada e expressa num além simbólico, um além a que hoje chamamos ser, uma realização de ser no sujeito. (LACAN, apud ZIZEK, 2009, p. 11).
\end{abstract}

Sob este prisma, o sujeito lacaniano também apresenta o próprio Real não representável como seu estatuto, de modo que a Coisa real é primordialmente o núcleo impossível do sujeito. Assim, “[...] devemos aplicar ao sujeito lacaniano a definição de Coisa como aquele aspecto do Real que carece de significante” (ZIZEK, 2009, p. 10).

Ademais, impõe-se o fato de o sujeito se suportar em um corpo no qual não se inscreve apenas a linguagem, mas que também é afetado pela dinâmica das pulsões. A propósito, inspirando-se em Jacques-Alain Miller, o próprio Zizek (2008, p. 88) destaca que é preciso fazer uma distinção entre, por um lado, a falta que é espacial e designa um vazio dentro de um espaço e que, enfim, estrutura o desejo, e, por outro lado, o buraco que é algo bem mais radical, "designando o ponto em que a própria ordem espacial se rompe (como no 'buraco negro' da física)”. Ou seja, sob esta perspectiva, impõe-se, segundo Zizek (2008, p. 89), uma diferença entre desejo e pulsão:

O desejo se baseia em sua falta constitutiva e a pulsão circula em torno de um
buraco, de uma lacuna na ordem do ser. Em outras palavras, o movimento
circular da pulsão obedece à estranha lógica do espaço curvo, em que a menor
distância entre dois pontos não é uma reta, mas uma curva: a pulsão 'sabe' que
o caminho mais curto para atingir seu alvo é circular em volta do objeto-meta.

Nesta perspectiva, por um lado, o objeto a lacaniano se sobrepõe à sua própria perda, ao surgir no próprio momento da perda - de modo que todas as suas encarnações fantasmáticas, de seios a vozes e olhares, são figurações metonímicas do Vazio, do nada. Assim, ele continua dentro do horizonte do desejo, pois o verdadeiro objeto-causa do desejo é o Vazio preenchido por suas encarnações fantasmáticas. Por outro lado, porém, como enfatiza Lacan, o objeto a também é objeto de pulsão, sendo que neste caso a relação se torna bem diferente. A propósito, como destaca Zizek (2008, p. 90):

Embora o vínculo entre objeto e perda seja importantíssimo em ambos os casos, no caso do "objeto a", como objeto-causa do desejo temos um objeto que originalmente está perdido, que coincide com a própria perda (...); ao passo que, no caso do "objeto a" como objeto de pulsão, o "objeto" é 


\begin{abstract}
diretamente a própria perda, [ou seja,] na passagem do desejo para a pulsão, vamos do objeto perdido à própria perda como objeto. [Assim], o estranho movimento chamado de "pulsão" não é impelido pela busca 'impossível' do objeto perdido; ele é o impeto de encenar diretamente a 'perda' em si - a lacuna, o corte, a distância. Aqui, há uma dupla distinção a fazer: não só entre o 'objeto a' em sua condição fantasmática e pós-fantasmática, mas também, dentre desse mesmo campo pós-fantasmático, entre o objeto-causa perdido do desejo e o objeto-perda da pulsão.
\end{abstract}

Desse modo, a própria pulsão de morte, segundo Zizek (2008), não pode ser confundida com a ânsia de autoaniquilação, com o impulso cego de autoextermínio ou com uma busca de retorno à ausência inorgânica de toda tensão de vida. Ao contrário, trata-se aí do verdadeiro oposto de morrer. Ou seja, segundo Zizek, com base em Freud:

Trata-se "[...] do terrível destino de permanecer preso no ciclo repetitivo e interminável de perambular com culpa e dor. [...] [Enfim, pulsão de morte] é o nome que Freud dá [...] ao sinistro excesso de vida, à ânsia 'não morta' que persiste além do ciclo biológico de vida e morte, de geração e deterioração. [Assim,] a maior lição da psicanálise é que a vida humana nunca é 'só vida': os seres humanos não estão simplesmente vivos, eles estão possuídos pela estranha pulsão de gozar a vida em excesso, apegados a um excedente que se projeta para fora e perturba o funcionamento comum das coisas" (ZIZEK, 2008, p. 90).

Portanto, é no desejo que o objeto positivo e parcial é o substituto metonímico do Vazio da Coisa impossível, pois é no desejo que a aspiração de plenitude se transfere para estes objetos parciais, e é isto que Lacan chamava de metonímia do desejo.

Por outro lado, pulsão não é a ânsia infinita de se reunir à plenitude da Coisa maternal e que não se realiza por permanecer a pulsão fixada a um objeto parcial. A pulsão não é um impulso universal freado e fragmentado em direção à Coisa incestuosa. Ela é, segundo Zizek (2008), o próprio freio, o freio do instinto.

A matriz elementar da pulsão não é transcender todos os objetos particulares em direção ao Vazio da Coisa, a qual então só fica acessível em seu substituto metonímico, mas sim [a matriz elementar da pulsão relaciona-se à] nossa libido que fica 'presa' a um objeto particular, ficando [a própria pulsão] condenada a circular para sempre em torno dele. (ZIZEK, 2008, p. 91).

\title{
4. O Sujeito do Inconsciente, o "Real Da Jouissance", a "Foraclusão" do Sujeito no Conhecimento Científico e o Ponto Zero e Evanescente do Cogito
}

Voltando à abordagem da noção de sujeito, Zizek (2009) ainda observa que o sujeito lacaniano designa um hiato no simbólico, de modo que seu estatuto integra o registro do "Real". Ou seja, só podemos abordar o "Real da jouissance" quando relativizamos o domínio da morada do Ser, ou seja, da linguagem, para assim nos darmos conta dos furos e das fissuras no registro simbólico, por onde o Real traumático 
oculto emerge e por onde também emerge o Real da jouissance. Por isso, para Lacan, também o cogito não pode ser reduzido à autotransparência do pensamento puro, porque ele é o sujeito do inconsciente, ou seja, a distância/corte na ordem do Ser.

Segundo Zizek (2009), se Lacan em seus primeiros seminários, não partilha dos enfoques que estabelecem uma distância entre pensamento (cógito) e ser, subsequentemente, a partir do seu seminário sobre a lógica do fantasma, Lacan passa a ler a verdade do cogito ergo sum de Descartes de modo mais radical, visto que nos seminários anteriores o autor jogou indefinidamente com variações que subvertiam o sujeito. Mas, quando assume uma interpretação mais radical do cogito cartesiano, Lacan passa a descentrar o Ser em relação ao pensamento, ao dar-se conta de que o "Não estou onde penso", o núcleo do meu ser, não reside na minha (auto) consciência. Em seguida, segundo Zizek (2009, p. 13), contudo, Lacan apercebeu-se do seguinte:

De que essa leitura deixava o campo inteiramente aberto para a irracional
Lebensphilosophie (Filosofia da vida), tópico da Vida mais profunda do que o
mero pensamento ou a linguagem, o que vai contra a sua tese fundamental,
segundo a qual o inconsciente freudiano está estruturado como uma linguagem,
de modo inteiramente discursivo. Portanto, passou para um muito mais
refinado "Penso onde não estou", que descentra o pensamento em relação ao
meu Ser, [em relação] à consciência da minha completa presença: o
Inconsciente é o Outro Local [...] puramente virtual [onde persevera] um
pensamento que escapa ao meu Ser [...]. O que todas estas versões partilham é
a focalização na distância entre cogito e sum, entre pensamento e ser. [Sendo
que] o propósito de Lacan consistia em minar a ilusão da sua sobreposição,
apontando para uma fenda na aparente homogeneidade pensamento-ser.
Assim, Lacan "[se agarra] ao mais radical ponto zero do cogito cartesiano,
como ponto de intersecção negativa entre ser e pensamento: o ponto
evanescente em que Não penso E não sou. [Ou seja, em que] NÃO SOU [...]
uma substância, uma coisa, uma entidade; [pois,] na ordem do Ser, estou
reduzido a um vazio, a um hiato, a uma abertura.

Por outro lado, referente à ciência moderna, cabe enfatizar que esta contribuiu para a emergência do sujeito moderno. Porém, o discurso da ciência pressupõe a foraclusão do sujeito - pois, no campo da ciência, o sujeito é reduzido ao ponto zero, visto que uma proposição científica deve ser válida para todos os que repetirem a mesma experiência (ZIZEK, 2009). Ademais, no momento em que incluirmos a posição de enunciação do sujeito do inconsciente, nos retiramos do campo da ciência - pois a construção científica se caracteriza pela incorporação de uma lógica de ocultação imaginário-simbólica dos excessos, das faltas e das inconsistências que emergem por entre as fendas do Simbólico na forma de um Real espectral. Na ordem do conhecimento, a ciência é estruturada a partir de princípios racionalistas, de leis gerais e em experimentos matemáticoquantitativos e empiristas que impõem uma borda 
protetora na forma de um cinturão de coerência linguístico-simbólica contra a emergência de fragmentos traumáticos decorrentes do registro do Real impossível. Assim, quando nos afastamos do discurso científico para entrarmos em uma sabedoria que emerge de outro local (o inconsciente), acessamos um saber não totalizante. Ou seja, o conhecimento científico se dá na intersecção do imaginário e do registro do simbólico, instituindo a representação como forma de identidade e totalidade, ocultando a emergência do furo e da lacuna no conhecimento. Ou seja, a representação da ciência adquire uma conformação coerente a partir da articulação conceitual em torno de teses empiricamente testadas, que são em seguida assumidas como verdades científicas.

No cerne desta padronização, a representação científica adquire uma máscara de formalização que impõe a marca de uma determinada arrogância em relação às formas de saber provenientes das formações do inconsciente e de outras formas fragmentárias e poéticas de sabedoria, relegando-as à insignificância.

De acordo com Zizek (2010), a verdade, na perspectiva lacaniana, não pode ser dita toda, pois faltam palavras para que isto seja possível. Dizer toda a verdade é materialmente impossível, porque dela não é possível simbolizar o seu núcleo oculto traumático. Assim, não é possível uma visão de mundo totalizante, pois não é a partir do caráter formalizado do discurso que a verdade se insinua, mas é precisamente quando o discurso falha e as palavras tropeçam que se revela um semidizer da verdade perturbadora entrelaçada com o desejo recalcado no nosso inconsciente. Ou seja, o saber do inconsciente tem relação com o sujeito evanescente da enunciação inconsciente, que é distinto do sujeito da ciência que propicia o acesso a um conhecimento dirigido pelo uso da razão. O saber próprio do inconsciente, ademais, não tem a ver com um acúmulo de conhecimentos como ocorre com o conhecimento científico (LIMA, 2011).

Ao contrário do conhecimento presente no discurso universitário e científico - em que o conteúdo se traduz em princípios claros e distintos, sistematicamente articulados no sentido lógico -, o discurso psicanalítico revela que todo saber ou conhecimento é nãotodo, pois apresenta lacunas, furos e falhas incontornáveis e, portanto, não superáveis por quaisquer suturas operadas pelo discurso racional e científico. Ou seja, as formações do inconsciente e as formações patológico-sintomáticas - as quais exprimem uma realização do desejo do pensamento recalcador sob a forma autopunitiva -, mediante o trabalho do sujeito no processo transferencial psicanalítico, facultam o acesso a um saber não totalizante, que as formações cognitivas racionais das ciências ignoram e abordam como sendo irracional e insignificante. 
No mundo moderno, a ciência e seu braço que é a tecnologia se tornam os representantes fulcrais do discurso sociosimbólico, substituindo o papel de nomeação do sujeito, introduzindo novos objetos, atados ao entrecorte dos registros do imaginário e do simbólico, visualizados como fatores de sutura ou de obliteração do elemento incontornável da falta, que está instalado na própria base do desejo do sujeito da enunciação, contribuindo, desse modo, para o surgimento de novas formas de sintomas sociopatológicos, tais como a toxicomania e a depressão. Ou seja, a ciência e a tecnologia visam responder ao que há de insuportável frente ao não-saber que emerge por entre os limiares dos recortes-bordas dos objetos de conhecimento científico.

Segundo o pensamento lacaniano, se apresenta uma disjunção nuclear dos campos da verdade e do saber-ciência. Nesta perspectiva, segundo Sanada (2004, p. 2): Torna-se importante ressaltar que essa disjunção é o que marca a própria
constituição do sujeito, dividido, uma vez que estabelece uma relação [de
proporção ou] de razão entre $S 1$ e S2, ponto este que, a princípio, equivaleria
aos discursos da ciência e de psicanálise em sua essência. No entanto, uma
diferença fundamental se coloca, e diz respeito à exclusão [ou foraclusão] do
sujeito por parte da ciência, sujeito este que a psicanálise busca reintroduzir
em seu discurso, contemplando a dimensão da verdade como não-toda a partir
da fala, e a dimensão do saber naquilo que se articula à cadeia significante.
(2004, p.2).

Ainda no que tange ao NÃO PENSO do ponto zero e evanescente do cogito cartesiano, cabe observar que Lacan aceita paradoxalmente a tese heideggeriana de que a ciência moderna matematizável não pensa - mas para ele, isso significa que ela escapa ao quadro da ontologia, do pensamento como Logos correlativo ao Ser (ZIZEK, 2009).

Ou seja, na perspectiva lacaniana:

\begin{abstract}
Como puro cogito, eu não penso e estou reduzido a uma pura forma de pensamento que coincide com seu oposto, isto é, uma forma sem conteúdo e que é, como tal, não-pensamento. A tautologia do pensamento é autocancelada da mesma maneira do que a tautologia do ser; por isso, para Lacan, o "Sou aquele que Sou" enunciado pela sarça ardente a Moisés no Monte Sinai, aponta para um Deus além do Ser, Deus como Real (ZIZEK 2009, p. 13).
\end{abstract}

Ademais, para equacionar a problemática do sujeito, Zizek aproxima Hegel e Lacan para deles extrair uma teoria do sujeito fundada na ideia de negatividade. O "Real" lacaniano é impossível de ser simbolizado ou totalizado, e, por conseguinte, nesta perspectiva o sujeito é constituído por uma falta estrutural que é decorrente de sua inscrição na linguagem, a qual por sua vez, não consegue inscrever os traumas ocultos do "Real". Instala-se aí uma ausência radical na própria estrutura constitutiva do sujeito que é assim impossibilitada de alcançar uma plenitude ontológica. A ideologia no plano 
da vida social e a fantasia no cerne da subjetividade funcionam como mecanismos de suturamento dessa falha incontornável, instaurando uma ilusão em forma de totalidade.

Como esclarece Zizek (1996A, p. 26):

A realidade nunca é diretamente "ela mesma"; ela só se apresenta através de sua simbolização incompleta e falha. As aparições espectrais emergem justamente nessa lacuna que separa perenemente a realidade e o "real", e em virtude da qual a realidade tem o caráter de uma ficção (simbólica): o espectro dá corpo àquilo que escapa à realidade (simbolicamente estruturada).

Em suas derradeiras reflexões, uma tese central de Lacan aponta

[...] que existe uma possibilidade de o sujeito obter alguns conteúdos, algum tipo de consistência positiva, também fora do 'grande Outro', fora da rede simbólica alienante. Essa outra possibilidade é a oferecida pela fantasia, equacionando o sujeito com um objeto da fantasia" (ZIZEK, 1996B, p.324).

Ou seja, o sujeito adquire suas características particulares não apenas por um mandato simbólico que lhe é imposto por uma rede de relações intersubjetivas da qual ele faz parte - porque se assim fosse, o sujeito não passaria de um mero vácuo, um espaço vazio a ser totalmente preenchido pelo conteúdo do "grande Outro" e pelos "pequenos outros", o que resultaria em uma alienação radical e inexorável do sujeito. Assim, a espinha dorsal da "realidade de fantasia" do sujeito de alguma forma mantém uma conexão com o "Real" do desejo do sujeito, dando uma consistência positiva a ele fora da rede simbólica alienante.

\section{Notas Finais sobre a Subjetividade Hegeliano-Lacaniana de Zizek e uma Breve Nota sobre a Educação Enquanto ato Político-Educativo}

Quando Zizek (2009) recorre ao idealismo alemão (Kant, Schelling e Hegel) e à psicanálise lacaniana, o seu interesse central recai sobre o diagnóstico de certa falta e também certo excesso na ordem do ser. Ou seja, há uma "loucura" indecifrável que é inerente à constituição da própria subjetividade como tal, que Kant conceitua como sendo a dimensão do mal "diabólico" e Schelling e Hegel a nomeiam respectivamente como a "noite do eu" e a "noite do mundo". O importante aí a ser resgatado é a reiterada ênfase na negatividade como pano de fundo inarredável presente em todo ser. Ou seja, esta é uma visão da subjetividade como algo que só pode vir a ser como uma passagem pela loucura, pelo seu núcleo traumático inconsciente, na tentativa permanente, mas de certo modo sempre fracassada, de impor uma integridade simbólica à ameaça sempre presente de desintegração e negatividade, no cerne da própria subjetividade. 
Segundo Zizek (2009), na psicanálise esse aspecto da subjetividade deslocada está atado ao conceito freudiano de "pulsão de morte", que emerge como efeito dessa lacuna ou furo insuperável na ordem do ser. A autonomia radical do sujeito se constitui de modo relacional a essa fissura que ameaça incessantemente sabotar a estrutura simbólica da subjetividade. Ou seja, o sujeito é um vazio constitutivo básico que impulsiona a subjetivação, mas que não pode, em última instância, ser preenchido plenamente em termos de conteúdo. Desse modo, o sujeito é simultaneamente faltoso, excessivo e barrado, não podendo encontrar um nome adequado na ordem simbólica, nem chegar a uma identidade ontológica plena. Usando as expressões de Lacan, o sujeito é "um efeito da linguagem", mas também "um espinho atravessado na garganta do significante". E, à medida que se liga à negatividade radical da pulsão de morte, o sujeito também reflete o mesmo tipo de tensão identificado no idealismo alemão:

\footnotetext{
O sujeito tanto é um movimento de distanciamento da subjetivação - o excesso que engolfa a coerência simbólica numa noite entrópica do mundo - quanto o impulso para a subjetivação, como maneira de escapar desse estado incômodo. (ZIZEK, 1999, p. 59).
}

A propensão ao excesso, à resistência e à distorção negativa, são os componentes que conferem um status humano ao sujeito e fincam um espinho na ordem simbólica. Ademais, é o conhecimento traumático a respeito de nós, que se mascara em projeções de fracasso, que nos impede de preencher por completo o vazio do sujeito barrado em nós. Mas, ao mesmo tempo, esta própria resistência-excesso diante da subjetivação - e o consequente impulso de resolver questões impossíveis concernentes à identidade, ao destino, à divindade e assim por diante - faz com que, paradoxalmente, os sujeitos estejam abertos à possibilidade de desenvolver novas formas de subjetivação. Assim, o sujeito é, simultaneamente, a condição transcendental de possibilidade e de impossibilidade de todas as formas de subjetivação contingente (Cf. DALY, 2006, p. 7- 30).

Portanto, na contramão das diversificadas leituras pós-estruturalistas e desconstrucionistas que se alastraram na filosofia contemporânea - nas quais o traço enfático recai numa noção do ser múltiplo que sempre se configura provisoriamente em planos deslizantes de diferença, com a ideia de sujeito tendo se tornado bastante obsoleta, já que ele supostamente evoca a imagem de uma identidade cartesiana unificada -, Zizek (2006) enfatiza sistematicamente que o sujeito não é alguma entidade substancial nem um lócus específico, mas que “[...] o sujeito existe, antes, como uma 
dimensão eterna de resistência-excesso em relação a todas as formas de subjetivação". (ZIZEK, 2006)

Por outro lado, a leitura de Zizek (2009) sobre a questão da identidade em Hegel se contrapõe à objeção lacaniana de que Hegel promove um sujeito preso em sua autoidentificação, pois para Zizek a tríade hegeliana - tese, negação e negação da negação envolve a internalização da não-identidade ou da diferença. Ou seja, o filósofo esloveno está bastante focado com o ininterrupto e irrequieto movimento da dialética hegeliana, que mais funciona como um processo interminável de tentativas repetitivas e sempre fracassadas em fixar experiências históricas reconciliatórias. Isto mostra, conforme Zizek, que a mediação absoluta do conceito é uma ilusão não-hegeliana. Ademais, a partir de sua controvertida interpretação da dialética hegeliana, Zizek concentra a sua atenção também sobre a implicação que a não-identidade ou a diferença tem sobre o movimento da identidade; ou seja, tão logo algo aproxima a identidade consigo mesma isto também se reverte em seu oposto, em sua diferença. É tomando em conta este processo, incessante e interminável, que Zizek estabelece repetidamente a ilustração paradoxal de que atualmente a própria tautologia é uma forma de contradição.

Nesta perspectiva, segundo Zizek (2008), a afirmação de que "a lei é a lei”, da mesma forma que sugere que a única razão para obedecer à lei é que ela é imposta sobre nós - e que simultaneamente há nisso algo inerentemente traumático, violento, arbitrário e, finalmente avesso à própria lei -, ela também sugere que toda identidade acaba se identificando com o seu oposto, como na equação hegeliana: $O$ espírito é um osso, ou seja, em sua completa inércia, o crânio (ou o cérebro) nos fornece a representação do Espírito, o qual já desde antes animou àquele.

Ou seja, para Zizek (1993), a interpretação hegeliana deve ser feita - não sob o prisma de que a consciência, primeiro relaciona-se ou liga-se a um objeto externo ou a outro conteúdo fora de si, para apenas então internalizar de forma totalizante e plena este objeto ou conteúdo -, mas, ao contrário, de que a minha consciência se constitui no processo do meu repetido fracasso em subsumir toda e qualquer diferença resistente. Portanto, é precisamente porque o objeto externo retém inexoravelmente sua diferença, embora não de forma rigidamente fixa, que a autoconsciência pode seguir o caminho do movimento de reflexão do sujeito para o objeto e de volta para si mesmo.

Deste modo, Zizek (1993) traz Hegel para dentro de sua própria perspectiva, para o que antes disso já fizera referente ao pensamento de Lacan. Sob este prisma, autoconsciência é o completamente oposto de autotransparência. Ou seja, eu tenho

\begin{tabular}{|l|l|l|l|l|} 
Revista Dialectus & Ano 1 & n. 1 & Julho-Dezembro 2012 & p. 200-218 \\
\hline
\end{tabular}


consciência de mim mesmo somente até o ponto que fora de mim existe um lugar onde a verdade sobre mim está articulada. Assim, a própria identidade resulta de uma reflexão, pela qual são depositadas de volta sobre cada coisa a ser identificada, na forma de uma contradição interna, as diferenças, graças às quais a coisa em foco conserva o aspecto do não-idêntico ou do não assimilável frente ao próprio conceito de identidade.

Portanto, Hegel não pode ser abordado como o último filósofo da mediação conceitual absoluta, onde tudo é subordinado à identidade, à totalidade e ao conceito. Assim, como transparece na leitura de reconhecimento do antagonismo na Ciência da Lógica e na compreensão da Essência em Hegel, fica difícil endossar a interpretação ontoteológica e teleológica franco-kojeviana sobre o modelo de pensamento de Hegel. Longe de representar a história da progressiva superação do antagonismo, a dialética hegeliana apresenta, conforme Zizek (2009), um sistemático reconhecimento das falhas e do fracasso de todas estas tentativas. Ou seja, segundo esta interpretação, o "conhecimento absoluto" hegeliano denota antes uma posição subjetiva que aceita a contradição como uma condição interna indissolúvel de toda forma de identidade. Assim, a reconciliação na dialética hegeliana não comporta uma subsunção "panlogística" de toda a realidade no Conceito, mas o consentimento final de que o Conceito é "não-todo", ou seja, de que há uma lacuna impossível de ser plenamente suturada, e um elemento de não identidade que resiste a todas as tentativas fracassadas de subsumi-lo em uma totalidade harmônica ou sintética. Assim, Hegel é um pensador que de certo modo antecipa o "Real" lacaniano, impossível de ser simbolizado.

Conforme Zizek (2009), Hegel é antes um filósofo da contingência do que do absoluto, de modo que não é um arauto do progresso teleológico, pois é apenas no sentido retroativo que o resultado de sua dialética é visto como tendo sido necessário. Ou seja, Zizek insere a dialética hegeliana no modelo freudiano-lacaniano de causalidade retrospectiva - baseado nos conceitos de nachträglichkeit de Freud e de après-coup de Lacan. Porém, nestes termos, sob um olhar prospectivo a dialética hegeliana está sempre aberta ao acaso, ou seja, a uma compreensão perspectivista.

Para concluir esta reflexão, cabe observar que somente o fato de Zizek ter estabelecido um alinhamento tão heterodoxo do pensamento de Hegel, lhe permitiu argumentar que a verdadeira universalidade emerge de modo imanente do domínio concreto da particularidade histórica. Desse modo, longe de diminuir o aspecto da universalidade, a especificidade histórica é a chave reflexiva que permite a realização do universal. Assim, a aparente necessidade e inevitabilidade da marcha do Espírito 
absoluto hegeliano apenas é um efeito nachtäglich (a posteriori) em perspectiva: ao invés de um eterno e sempre preexistente esquema na forma de um projeto pré- configurado da materialização das formações históricas, o Espírito hegeliano somente aparece em sua necessidade para o approach fixo do olhar subjetivo retrospectivo - em afinidade com a própria colocação metafórica de Hegel de que "a águia de minerva só levanta vôo depois do anoitecer" - daqueles que inseridos em uma série contingente de eventos, os traduzem de modo retroativo vis-à-vis a uma formulação explicativa dos elementos de continuidade e descontinuidade de tais estruturas espirituais e históricas.

Por fim, referente a uma educação para a emancipação, cabe pontuar que esta só se afirma quando acompanhada pela democratização da riqueza e do poder na sociedade, envolvendo ações de ultrapassagem transformadora do status quo, enfim atitudes de ruptura com a "rede simbólica intersubjetiva alienante".

A educação, por um lado, tem uma característica de assimilação dos indivíduos ao constructo institucional socioeconômico, político, jurídico e cultural dominante, mediante a adequação e absorção dos indivíduos às relações de força institucionais e simbólicas imperantes na sociedade - envolvendo relações de produção, de mercado, de inserção profissional, jurídico-institucionais e de comunicação - em um contexto de dominação e de exploração de classes, étnico-raciais e de gênero.

Porém, o ato educativo por excelência é aquele que é, ao mesmo tempo, um ato político individual e coletivo de ruptura com situações opressoras cristalizadas, de injustiça, de marginalização social, enfim de falta de liberdade e de emancipação social. O autêntico ato pedagógico é também um ato político de subjetivação criativa, de redesenho simbólico em que o sujeito faz valer aquela partícula do Real e aquela dinâmica pulsional que funciona nele como um espinho na garganta da linguagem, inserindo-o corajosa, arriscada e incomodamente em uma dinâmica coletiva e intersubjetiva de transformação profunda e criativa da sociedade.

\section{Referências Bibliográficas}

DALY, Glyn. “Introdução: Arriscando o Impossível”. In: ZIZEK, Slavoj \& DALY, Glyn. Arriscar o Impossível: conversas com Zizek. São Paulo, Martins Fontes, 2006.

LIMA, Jamille. “A especificidade do saber na operação analítica”. On-line ISBN 97885-60944-35-4. An 8 COLÓQUIO do LEPSI IP/Fe-USP, 2011. 


\section{Hildemar Luiz Rech}

SANADA, Elizabeth dos Reis. "A 'Verdade' da Ciência a partir de uma Leitura Psicanalítica”. Rev. de Psicologia USP. 2004, 15(1/2), 183-194.

ZIZEK, Slavoj. Como Ler Lacan. Rio de Janeiro, Zahar, Editores, 2010.

Relógio D’Água, 2009.

O Sujeito Incomodo: O centro ausente da ontologia política. Lisboa,

A Visão em Paralaxe. São Paulo, Boitempo, 2008.

. The ticklish subject. Londres, Verso, 1999.

. The plague of fantasies. Londres, Verso, 1997.

" "Introdução: O espectro da ideologia". In: ADORNO, Theodor et. al. ZIZEK, Slavoj (org.). Um Mapa da Ideologia. Rio de Janeiro: Contraponto, 1996A, pp.7-38.

. “Como Marx inventou o sintoma?". In: ADORNO, Theodor et. al. ZIZEK, Slavoj (org.). Um Mapa da Ideologia. Rio de Janeiro: Contraponto, 1996B, pp.297-331. 1993. . Tarrying with the negative. Durham, Carol. Norte, Duke Univ. Press, ; DALY, Glyn. Arriscar o Impossível: conversas com Zizek. São Paulo, Martins Fontes, 2006. 